\title{
EXPLORING MALAYSIAN UNDERGRADUATES' DECISION-MAKING PATTERNS IN DIFFERENT SITUATIONAL CONTEXTS
}

\author{
Khazriyati Salehuddin* \\ Centre for Research in Language and Linguistics, Faculty of Social Sciences \\ and Humanities, Universiti Kebangsaan Malaysia, \\ 43600 Bangi, Selangor, Malaysia \\ E-mail: khazudin@ukm.edu.my
}

Published online: 30 July 2021

To cite this article: Salehuddin, K. 2021. Exploring Malaysian undergraduates' decision-making patterns in different situational contexts. International Journal of Asia Pacific Studies 17 (2): 217-247. https://doi.org/10.21315/ijaps2021.17.2.9

To link to this article: https://doi.org/10.21315/ijaps2021.17.2.9

\begin{abstract}
Decisions are made all the time. While the decisions that humans make should ideally be objective decisions, almost all the time the decisions that are made are influenced by many overlapping factors that vary from one situation to another. This includes decision maker's environment, their past experiences, cognitive biases, individual differences and belief in personal relevance. Past studies have shown that the decisions that individuals make can be linked to their social behaviours and/ or socio-economic status. Hence, the current study aims to explore the decisionmaking patterns of a group of Malay-English bilingual Malaysian undergraduates $(n=128)$ based on the decisions that they made when reading 48 situational statements that are either in Malay (24 statements) or English (24 statements). Sixtysix of these bilinguals were from the low-income group whereas the remaining 62 were from the high-income group. To explore their social behaviour, the situational statements were presented to them in three different themes, namely, "Dictatorship", "Jealousy" and "Charity", each with three different options for them to choose from. The statements were also presented with or without the inclusion of a Malay or a Western cultural element. Results show different decision-making patterns in the three different themes. However, although past studies showed that income group, language proficiency and the language used in which the studies are conducted play a role in decision-making, neither of these had significant impact on the decisions
\end{abstract}


that the respondents of the current study made. The findings from the current study suggest that there may be other factors that shaped the decision-making patterns of Malaysian undergraduates today.

Keywords: bilinguals, decision-making, English, Malay, reading

\section{INTRODUCTION}

Almost everything that human beings do-from simpler or less complex tasks like choosing what to eat at the dinner table, to more complex ones like whether to rent a house or to buy it - requires decision-making. Decisions that are made for simpler tasks are typically made intuitively, which are done rather effortlessly and rather quickly, based on gut feelings and the norms; those that are made for more complex tasks involve deliberate thinking, and are done more rationally and rather analytically (Kruglanski and Giegerenzer 2011).

Technically, decision-making is a cognitive process that results in a belief or a course of action among two or more possible alternatives (Zsambok 1997) so as to arrive at a solution for a given problem (Panpatte and Takale 2019). It is the process of recognising and selecting the options based on the beliefs, orientation and values of the person who makes the decision. When making decisions, the decision makers will have to evaluate the options that are available to them and perhaps, narrow down the choices based on the different situations (Panpatte and Takale 2019) so as to ensure that the decisions that are made from the options given are the most appropriate decisions to the demand of the situation (Obi and Agwu 2017). If the decision makers have to make more than one choice, they will have to consider all the criteria that each option has simultaneously so as to enable them to rank the options in terms of how "attractive" the options are to the decision makers.

Four cognitive stages are involved when decisions are made (Nunes et al. 2015). Decision-making begins with the pre-processing stage, where understanding is built from information that are compiled from various sources and then proceeds to the explication stage, where the established understanding based on the compiled information is updated. Once this is done, the elimination stage takes place and this is when choices that have or bring no advantage when compared to other choices are removed. When the elimination is done, the final stage, which is the selection stage, takes place and this stage marks the completion of the decision-making process. 
Studies have shown that decision-making process is influenced by the decision maker's environment (e.g., Davidson and Yaneer 2006). Past studies have also shown a few factors that influence decision-making processes which in turn result in the choices that people make. According to Dietrich (2010), these factors include: (1) decision makers' past experiences (e.g., to avoid repeating past mistakes), (2) cognitive biases (e.g., thinking patterns based on observations and generalisations that may lead to memory errors, inaccurate judgements and faulty logic), (3) an escalation of commitment and sunk outcomes (i.e., how far are they willing to commit), (4) individual differences (e.g., age, socioeconomic status and cognitive abilities) and (5) belief in personal relevance.

\section{LITERATURE REVIEW}

To date, decision-making studies have been conducted from various disciplines including economy, psychology, neuroscience and language, with a majority of them being interdisciplinary in nature. Studies on socioeconomic status (SES) have shown that being in the lower-income group has an effect on individuals' decision-making. This is found to be true as, typically, those who are in the lower-income group constantly think relatively more about financial issues than their counterparts in the higherincome group. Their relative thinking about monetary issues may result in them making decisions based on their current financial situations. Since their counterparts in the higher-income group do not think about financial issues as much as they do, the decisions that individuals from the lowerincome group make may be different from those that individuals from the higher-income group make. A study conducted by Mani et al. (2013) has found that individuals show worse performance in cognitive activities when they are in poverty since they tend to focus their attention more on the monetary issues that they are facing. Deck and Jahedi (2015) as well as Mullainathan and Shafir (2013) suggest that the lower-income groups' poor performance in cognitive activities is due to resource scarcity because situations which require them to constantly think about their limited resources actually increase their mental bandwidths. Perera et al. (2021) proposed an event-related potential study to investigate how low-income groups' financial situation may impact their decision-making process. 
While the studies mentioned above suggest that the brain wave behaviours of individuals from the lower-income groups are different from their higher-income counterparts due to resource scarcity, there are also studies that have been conducted on individuals from different income groups to investigate whether or not the decisions they make are based on factors that are related to their behaviour with people around them. Due to the fact that being in the lower-income group or in the higher-income group is a socioecological consideration (Sheehy-Skeffington 2020), the decisions that individuals make tend to be shaped both by absolute resources (when the item is highly limited) as well as relative resources (when the item is temporarily limited) in comparison to others. This also suggests that the decisions that individuals make are influenced by the manner they interact with, or how they regard, other people who might be affected by the decisions they make. However, a study by Knafo-Noam and Markovitch (2015) highlights parenting role rather than societal role in shaping social behaviour; their findings suggest that through modelling and hands-on behaviours, parents can develop their children's prosociality (i.e., the behaviours that are intended to benefit others).

A study by $\mathrm{Li}$ (2017) is one of the few studies suggesting that the decisions that individuals make are influenced by their social behaviour. Individuals with a prosocial behaviour (as opposed to antisocial behaviour) refer to individuals with "a social behaviour that benefits other people or society as a whole" (Cherry 2018: 1), "rather than to benefit the self" (Twenge et al. 2007: 56). Prosocial behaviours often entail "risk or cost to the self, such as when one gives resources to others, waits in line, asks for or pays a fair price or risks one's life in battle. Yet, it is not irrational or self-destructive to perform such acts because, in the long run, belonging to the group provides immense benefits" (Twenge et al. 2007: 56).

As a result of their solicitude towards the feelings, well-being and the rights of other individuals around them, as well as their empathic feelings towards others, those who are prosocial tend to behave in ways that would help and benefit people other than themselves by comforting, sharing and cooperating with them (Batson 1998). Although their behaviour may seem altruistic (i.e., willing to sacrifice their own income so that the income of the other individuals can be increased [Moreno et al. 2019]), prosocial behaviour is not always altruistic because such a behaviour may result from a variety of reasons, such as obligations, duty, guilt or even rewards (Sisco and Weber 2019).

To investigate the effect of language on decision-making, Li (2017) conducted a study on a group of Chinese participants, who are generally a 
group of people who are well-known for their collectivistic/more prosocial society, using games that revolved around the themes of Dictatorship, Jealousy and Charity. To measure if language has an effect on the preferences that individuals make, the games were conducted either in the Chinese language (to create the sense of collectivistic or more prosocial behaviour in the participants) or in the English language (to create the sense of individualistic or less prosocial behaviour in the participants). Li had hypothesised that the decisions that the participants would make in the preference games would be influenced by the language they used when communicating in the game. This hypothesis was made because the underlying cultural frame that comes together with the culture of the language was believed to be able to be activated when the language is being used. However, his results did not show such findings. An earlier study by Winskel et al. (2016), however suggests the use of a language different from the native language having an effect on the decisions made by the participants. Their study echoes Keysar et al.'s (2012) foreign-language effect, which suggests that the use of a foreign language results in a greater emotional distance than a native language.

Quite a number of other decision-making studies that make references to prosocial behaviours that are not related to culture have also been conducted. Rather than relating prosocial behaviours to cultural aspects, in some of these studies, prosocial behaviours are often related to the socioeconomic status of individuals.

Naturally, individuals from the lower-income group are expected to focus more on themselves and their immediate needs because of the fewer economic resources (e.g., Oakes and Rossi 2003) and fewer educational opportunities (Snibbe and Markus 2005) that they have. This group of individuals also have less access to social institutions (Oakes and Rossi 2003), which further makes them position themselves in the lower ranks within their society. They need to "take extra care with the resources" they have, "prioritising mental efforts toward behaviours that can meet the immediate shortfalls" (Sheehy-Skeffington and Rea 2017: 3). Because of the fact that they need to prioritise their own well-being over that of others, and because of the fact that "prosocial behaviour is costly, directing resources away from the self towards others", it is assumed that individuals from the lower-income group are less prosocial than their counterparts in the higher-income group (Piff et al. 2010). Kebede et al. (2018) also reported that lower-income individuals are less cooperative and have the tendency to decrease their contribution in public good games as a result of envy, a form of emotion that Moreno et al. (2019) used interchangeably 
with jealousy (although Creo [2019: 1] had earlier said that "envy involves wanting what we don't have and others do, while jealousy involves keeping what we have from losing it to another who want it").

However, quite a number of studies have shown that individuals from the lower-income group tend to be otherwise. In a study by Piff et al. (2010: 771), for example, individuals from the lower-income group acted in a more prosocial fashion in the sense that they were more generous, more charitable, more trusting and more helpful, which Piff and her colleagues attribute to "a greater commitment to egalitarian values and feelings of compassion".

In a more recent study, Sheehy-Skeffington and Rea (2017: 32) suggests that it is possible that being low in income leads one to feel less included in society at large and the institutions representing it (such as schools), but perhaps to feel a stronger sense of connection to others also sitting at the bottom of the socioeconomic spectrum.

In some of these studies, the attributes of those from the lowerincome groups have been described as prosocial because individuals from the lower-income group are seen as having greater compassion (Stellar et al. 2012) and as being altruistic (Piff et al. 2010). In such studies, the decisions that lower-income groups make are usually linked to the idea that "the socioecology of lower-income individuals shifts the mind to focus on the proximal on all four dimensions of psychological distance" (SheehySkeffington and Rea 2017: 9).

Psychological distance refers to an egocentric cognitive concept that separates the self from another person as us (proximal) and them (distal); the self from another place as here (proximal) and there (distal); the self from another time as now (proximal) and then (distal); the self from another event as true (proximal) and hypothetical (distal) (Trope and Liberman 2010). As mentioned earlier, past studies that investigate decision-making have shown that psychological distance can be used to explain how decision makers make decisions in various contexts, including in the context of poverty (Piff et al. 2010). Sheehy-Skeffington (2020: 773) adds that "increased dependence on others orients individuals to others' needs, which in turn gives rise to increased prosociality. Lower income individuals, given their dependence on others, should demonstrate greater prosociality because of an increased concern of others' welfare".

Based on the findings from past decision-making studies, the current study was conducted to explore the decision-making patterns of Malaysians when they read Malay-English bilingual situational statements that were presented to them. The situational statements were presented to 
them in three themes, following Li's (2017) study, namely, Dictatorship, Jealousy and Charity. It was hypothesised that the social behaviour of Malaysians would be different from one theme to another. Since past studies (e.g., Sheehy-Skeffington 2020; Piff et al. 2010) have shown that income group have different impacts on the decisions that humans make, it was also hypothesised that the decisions that individuals from different income groups make will be different from each other. In addition, $\mathrm{Li}$ (2017) had earlier hypothesised that the language used in situational games may influence the decisions that participants make because of the social behaviour of the community that speaks the language. Hence, the current study also hypothesised that there will be an interaction between the decisions made and the language used in presenting the situational contexts.

Malaysians are considered as a more collectivist culture than other anglo- or western-culture based on studies by Burns and Brady (1992), Bochner (1994), Keshavarz and Baharudin (2009) and Winskel et al. (2013). They are found to place more emphasis on values like harmony, sharing and caring for others. Results from Winskel et al. (2013) for example, showed that Malaysians caregivers, "exhibited a higher degree of interdependent self-construal than Anglo-Australian caregivers, which is consistent with other cross-cultural studies in which Malaysians have been identified as more interdependent than Australians" (p. 28).

This study was conducted based on the following working definitions. Firstly, the decisions that individuals make will reflect their social behaviour - the more they give, the more prosocial they are. Secondly, Malaysian undergraduates are not monolinguals, but are at least Malay-English bilinguals. Thirdly, Malaysians, like other Asian cultures, form a collectivistic culture. Finally, Malaysian undergraduates who come from a household with a total income of less than MYR3,500 are regarded as individuals coming from the lower-income group.

\section{METHODS}

\section{Respondents}

The data of the current study were collected from 128 respondents (112 female, 16 male) who responded to an online questionnaire on voluntary basis. The questionnaire was circulated online to undergraduates at the Centre for Research in Language and Linguistics at one public research 
university in Malaysia who were pursuing their bachelor degrees either in English language studies or in Linguistics. All of them are Malaysians who were accepted into the respective undergraduate programmes based on their performance in the Malaysian national level standardised examinations. Since the fact that the Malay language is taught as the national language and the fact that the English language is taught as a second language (ESL) underly the Malaysian Education policy, all respondents in this study are regarded as Malay-English bilinguals.

\section{Instrument}

A questionnaire was distributed online to all the undergraduate students at the Centre for Research in Language and Linguistics via the WhatsApp group of their respective undergraduate programmes. The questionnaire consists of two sections. The first section has seven questions on their background information (e.g., gender, age, proficiency in both the Malay and the English language, and estimated household income category - either below or above MYR3,500). The second section consists of 48 situational statements that were designed to investigate respondents' decision-making behaviour.

Of the 48 situational statements, 24 were situational statements presented in the Malay language whereas the other 24 were presented in the English language. The situational statements were designed based on the three themes mentioned in Li (2017), namely, Dictatorship (eight statements in Malay, eight statements in English), Jealousy (eight in Malay, eight in English) and Charity (eight in Malay, eight in English). Although the themes in Li's (2017) study were presented in the form of games, in the current study, the themes were presented in the form of situational statements. The situational statements were presented in different themes because the kinds of decisions that respondents would have to make would be different in different themes.

Situational statements that require respondents to decide how much to share a given amount of money between themselves and the other person are labelled as Dictatorship-themed statements because in this type of situations, the respondents were given the total freedom (like a dictator) to either split the money equally between themselves and the other, or to give a smaller amount to the other or to give a larger amount to the other. Situational statements which require respondents to decide how much to give to the other person are labelled as Jealousy-themed statements because 
in this type of situations, no matter how much they give to other person, the amount the respondents get would not change. Situational statements which require respondents to decide whether to be involved in a charity work immediately, later or not at all so that the other person will (or will not) benefit from the charity work the respondents do (or will not do) are labelled as Charity-themed statements.

Each of the situations presented to the respondents comes with three options from which respondents would decide which one of the three options they would choose as their most favoured solution. The options for the Dictatorship-themed statements were $50 \%-50 \%, 40 \%-60 \%$ and $60 \%-40 \%$ whereas the options for the Jealousy-themed statements were either an amount less, the same amount or an amount more than the amount that the respondents get (e.g., MYR20, MYR40 or MYR60). The options for the Charity-themed statements were either "No Charity Work", "Charity Work Today" and "Charity Work Later" with an amount attached to the answers. None of these options are incorrect options. They are there as options for the respondents to choose from based on what they think is the best option. The options were provided so that the decisionmaking patterns that the respondents make when reading the statements can be explored.

An example of situations and options for each of the themes are presented in Table 1.

Table 1: Situations E1 depicts Dictatorship-themed statements with the three options in the bullets, E2 for Jealousy-themed statements and E3 for Charity-themed statements

E1. You are given MYR100 to be shared with Hamidon. How much will you give Hamidon and how much will you keep for yourself?

- Hamidon: MYR50; You: MYR50

- Hamidon: MYR60; You: MYR40

- Hamidon: MYR40; You: MYR60

E2. An organisation has asked you to give either MYR200, MYR400 or MYR600 to Hamilton as a winter present. No matter how much you give Hamilton, the organisation will still be giving you MYR400 as your savings. How much will you give Hamilton?

- MYR200

- MYR400

- MYR600

E3. Your neighbourhood's Rukun Tetangga will give some money to Hamidon if you do some charity work for them. Which one will you choose?

- MYR0 if you do not do the charity work for them

- MYR500 if you do the charity work for them today

- MYR1,000 if you do the charity work for them 10 weeks from now 


\begin{tabular}{|l|c|c|c|c|c|c|c|c|c|c|c|c|c|c|c|c|c|c|c|c|c|c|c|c|}
\hline & \multicolumn{11}{|c|}{ MALAY } \\
\hline & A & A & B & B & C & C & D & D & A & A & B & B & C & C & D & D & A & A & B & B & C & C & D & D \\
& 1 & 4 & 1 & 4 & 1 & 4 & 1 & 4 & 2 & 5 & 2 & 5 & 2 & 5 & 2 & 5 & 3 & 6 & 3 & 6 & 3 & 6 & 3 & 6 \\
\hline NAME & & & & & & & & & & & & & & & & & & & & & & & & \\
\hline Malay & $\mathrm{I}$ & & & $\mathrm{I}$ & $\mathrm{I}$ & & & $\mathrm{I}$ & & $\mathrm{I}$ & $\mathrm{I}$ & & & $\mathrm{I}$ & $\mathrm{I}$ & & $\mathrm{I}$ & & & $\mathrm{I}$ & & $\mathrm{I}$ & $\mathrm{I}$ & \\
\hline English & & $\mathrm{I}$ & $\mathrm{I}$ & & & $\mathrm{I}$ & $\mathrm{I}$ & & $\mathrm{I}$ & & & $\mathrm{I}$ & $\mathrm{I}$ & & & $\mathrm{I}$ & & $\mathrm{I}$ & $\mathrm{I}$ & & $\mathrm{I}$ & & & $\mathrm{I}$ \\
\hline & & & & & & & & & & & & & & & & & & & & & & & & \\
\hline CULTURE & & & & & & & & & & & & & & & & & & & & & & & & \\
\hline Malaysian & & & & & $\mathrm{I}$ & & & $\mathrm{I}$ & & $\mathrm{I}$ & $\mathrm{I}$ & & & & & & $\mathrm{I}$ & & & $\mathrm{I}$ & & & & \\
\hline Western & & & & & & $\mathrm{I}$ & $\mathrm{I}$ & & $\mathrm{I}$ & & & $\mathrm{I}$ & & & & & & & & & & $\mathrm{I}$ & $\mathrm{I}$ & \\
\hline None & $\mathrm{I}$ & $\mathrm{I}$ & $\mathrm{I}$ & $\mathrm{I}$ & & & & & & & & & $\mathrm{I}$ & $\mathrm{I}$ & $\mathrm{I}$ & $\mathrm{I}$ & & $\mathrm{I}$ & $\mathrm{I}$ & & $\mathrm{I}$ & & & $\mathrm{I}$ \\
\hline & & & & & & & & & & & & & & & & & & & & & & & & \\
\hline AMOUNT & & & & & & & & & & & & & & & & & & & & & & & & \\
\hline Small & $\mathrm{I}$ & & $\mathrm{I}$ & & $\mathrm{I}$ & & $\mathrm{I}$ & & $\mathrm{I}$ & & $\mathrm{I}$ & & $\mathrm{I}$ & & $\mathrm{I}$ & & $\mathrm{I}$ & & $\mathrm{I}$ & & $\mathrm{I}$ & & $\mathrm{I}$ & \\
\hline Large & & $\mathrm{I}$ & & $\mathrm{I}$ & & $\mathrm{I}$ & & $\mathrm{I}$ & & $\mathrm{I}$ & & $\mathrm{I}$ & & $\mathrm{I}$ & & $\mathrm{I}$ & & $\mathrm{I}$ & & $\mathrm{I}$ & & $\mathrm{I}$ & & $\mathrm{I}$ \\
\hline
\end{tabular}

\begin{tabular}{|c|c|c|c|c|c|c|c|c|c|c|c|c|c|c|c|c|c|c|c|c|c|c|c|c|}
\hline \multicolumn{25}{|c|}{ ENGLISH } \\
\hline & \multicolumn{8}{|c|}{ DICTATORSHIP } & \multicolumn{8}{|c|}{ JEALOUSY } & \multicolumn{8}{|c|}{ CHARITY } \\
\hline & $\mathrm{E}$ & $\mathrm{E}$ & $\mathrm{F}$ & $\mathrm{F}$ & G & $\mathrm{G}$ & $\mathrm{H}$ & $\mathrm{H}$ & $\mathrm{E}$ & $\mathrm{E}$ & $\mathrm{F}$ & $F$ & G & G & $\mathrm{H}$ & $\mathrm{H}$ & $\mathrm{E}$ & $\mathrm{E}$ & $\mathrm{F}$ & $\mathrm{F}$ & G & G & $\mathrm{H}$ & $\mathrm{H}$ \\
\hline & 1 & 4 & 1 & 4 & 1 & 4 & 1 & 4 & 2 & 5 & 2 & 5 & 2 & 5 & 2 & 5 & 3 & 6 & 3 & 6 & 3 & 6 & 3 & 6 \\
\hline \multicolumn{25}{|l|}{ NAME } \\
\hline Malay & I & & & I & $\mathrm{I}$ & & & $\mathrm{I}$ & & 1 & I & & & I & I & & I & & & I & & $\mathrm{I}$ & I & \\
\hline English & & 1 & I & & & 1 & $\mathrm{I}$ & & 1 & & & 1 & 1 & & & 1 & & $\mathrm{I}$ & I & & 1 & & & I \\
\hline & & & & & & & & & & & & & & & & & & & & & & & & \\
\hline \multicolumn{25}{|l|}{ CULTURE } \\
\hline Malaysian & & & & & 1 & & & I & & 1 & I & & & & & & I & & & I & & & & \\
\hline Western & & & & & & 1 & $\mathrm{I}$ & & 1 & & & I & & & & & & & & & & 1 & 1 & \\
\hline None & I & I & I & 1 & & & & & & & & & 1 & 1 & I & I & & $\mathrm{I}$ & I & & I & & & I \\
\hline & & & & & & & & & & & & & & & & & & & & & & & & \\
\hline \multicolumn{25}{|l|}{ AMOUNT } \\
\hline Small & 1 & & 1 & & 1 & & 1 & & 1 & & 1 & & 1 & & 1 & & 1 & & 1 & & 1 & & 1 & \\
\hline Large & & 1 & & 1 & & 1 & & 1 & & 1 & & 1 & & 1 & & 1 & & I & & 1 & & 1 & & I \\
\hline
\end{tabular}

Figure 1: A snapshot of the features of all 48 situational statements presented to the respondents. Situation E1, for example, is a situation presented in the English language, featuring a Malay name (i.e., Hamidon) and no cultural element in it with a smaller amount of money (i.e., MYR40, MYR50 or MYR60, and not MYR400, MYR500 or MYR600) for the respondents to decide upon (as shown in Table 1 earlier).

Apart from the fact that the situational statements were either in the Malay language or in the English language, the situations presented had either a Malay name (i.e., Hamidon) or an English name (i.e., Hamilton) in each of them, with or without the inclusion of a Malay cultural element (e.g., duit raya) or Western cultural element (e.g., cheerleading club) in the statements. Each of the situational statements comes together with 
an amount of money, some in a relatively smaller amount, and some in a relatively larger amount following the statement, as illustrated in Table 1. Figure 1 summarises the features of all 48 situational statements presented to the respondents.

The Malay version of the situational statements was presented first (Situations 1-24) and this version was followed by the English version (Situations 25-48) to create a framing effect mentioned in Li (2017). They were validated by a Malay-English bilingual researcher and lecturer from a research university in Malaysia who teaches and publishes in both languages. The situational statements were presented in a random but fixed order to ease the data analysis process. The questionnaire was then transferred onto the Google Form for easy distribution and for a higher rate of responses. A web link was created from the Google Drive once the questionnaire was ready so as to make the distribution of the questionnaire possible.

The questionnaire then was piloted on three Malay-English bilingual tertiary students from the same age range. The link to the questionnaire was sent to them via WhatsApp to check if the link works and if the instruction, questions and situational statements in the questionnaire are clear. All three indicated that they understood the instructions clearly regarding what they had to do and all of them responded to the questionnaire almost immediately after receiving them.

\section{Procedure}

Ethics Approval (UKM PPI/111/8/JEP-2018-339) was obtained before the commencement of this research. A WhatsApp message with a link to the survey questionnaire in the form of a Google Form was sent to the undergraduates of both the English Language Studies and the Linguistics Programmes through their respective programmes' WhatsApp groups.

Respondents were told that there were no wrong answers to each situational statement and that they need to choose one answer that they think is best for each situational statement. Once they have completed the questionnaire they were told to click on the "send" button. An automatic acknowledgement statement would then appear on their screen, thanking them for their participation. 


\section{Analysis of Data}

Responses from each respondent were automatically recorded by Google Form and the data was converted into a Google Spreadsheet. Data from the Google Spreadsheet were later downloaded as an Excel (.xls) file, which were later transferred into SPSS for quantitative analysis.

\section{RESULTS}

\section{The Demographic Data}

For this study, 128 Malay-English bilingual Malaysian undergraduates responded to the questionnaire. Based on the demographic data received, the respondents' age ranged between 20 and 27 years old $(M=22.21$, $\mathrm{SD}=1.127)$. For language proficiency, $62(48.4 \%)$ of the respondents regarded themselves as Malay-English bilinguals who are more proficient in the Malay language than the English language whereas another $66(51.6 \%)$ regarded themselves as Malay-English bilinguals who are either more proficient in the English language than in the Malay language, or are equally proficient in both the English and the Malay languages. Apart from that, 63 of the respondents fall under the higher-income group whereas the other 62 fall under the lower-income group. Figure 2 presents the breakdown of the undergraduates' income group in the form of a pie-chart.

\section{Income Group}

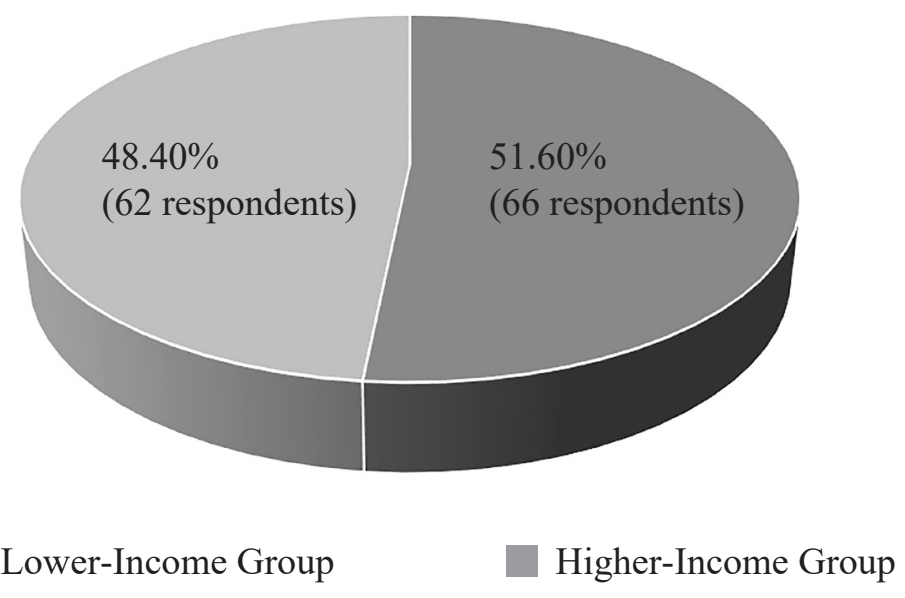

Figure 2: Income group profile gathered from the respondents. 
In order to measure the internal consistency (i.e., reliability) of the questionnaire, Cronbach's alpha reliability statistics was conducted. The overall reliability on all 55 items, the Cronbach's alpha value was 0.949. This indicates an excellent level of internal consistency in all the items.

\section{Social Behaviour Based on the 48 Situational Statements}

\section{Theme differences}

In order to explore the social behaviour of the respondents, repeated measures analysis of variance (ANOVA) was conducted on the responses given by the respondents for each theme, namely Dictatorship, Jealousy and Charity. As mentioned earlier in the methodology section, respondents had to choose from the three options provided in each situational statement and the choice they make would reflect their decision-making patterns.

Results show that for the Dictatorship-themed situational statements, a total of 459 responses were recorded for the $40 \%-60 \%$ (i.e., a smaller amount for the other person) option, 1,521 responses for the $50 \%-50 \%$ (i.e., the same amount for the other person) option, and 68 responses for the $60 \%-40 \%$ (i.e., a larger amount for the other person) option. Repeated measures ANOVA shows that there is a significant difference in the decisions made by the respondents for the Dictatorship-themed situations $F(1.23,155.95)=108.79, p<0.001$. Results shows that the participant's choice of $60 \%-40 \%$ was significantly lower than the $40 \%-60 \%$ option $\left(\mathrm{Mean}_{\text {diff }}=-3.06, \mathrm{SE}=0.58, p<0.001\right)$ which in turn was significantly lower than the 50\%:50\% option, $\left(\mathrm{Mean}_{\mathrm{diff}}=-8.30, \mathrm{SE}=1.07, p<0.001\right)$. This suggests that when making decisions on Dictatorship-themed situational statements, respondents were least inclined to give a larger share of money to the other person and have the smaller share of money for themselves instead. Although a great majority of the respondents prefer to split the amount they get equally with the other person, there were also those who were more inclined to share a smaller amount of the money to the other person so that they can keep a larger share for themselves. Figure 3 shows the total number of responses that each answer choice received from the respondents for the Dictatorship-themed situational statements. 


\section{Dictatorship-Themed Situational Statements}

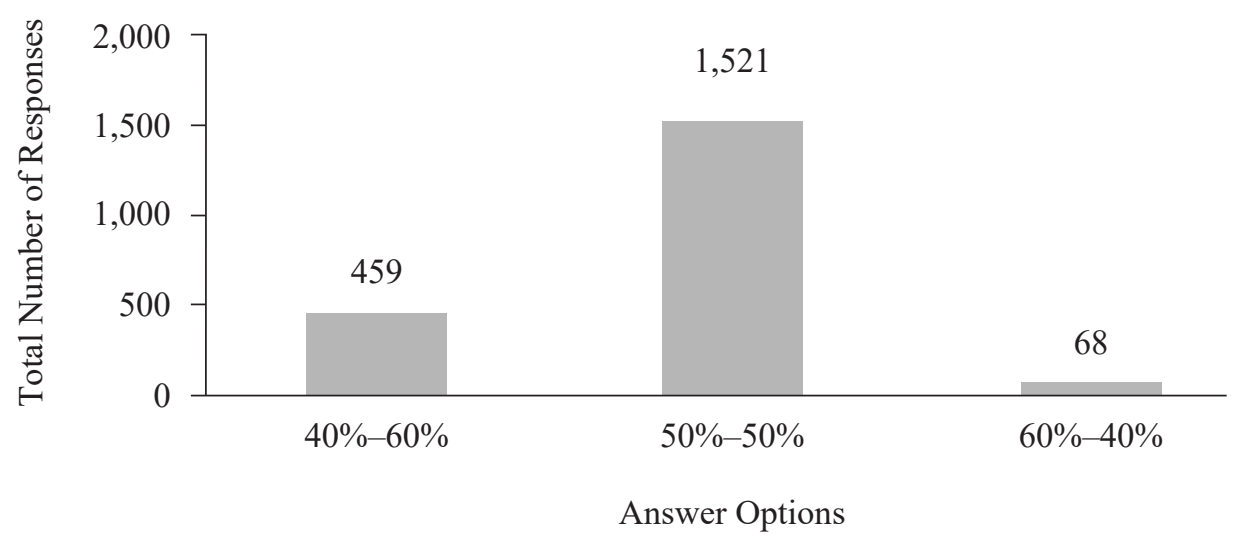

Figure 3: Total number of responses that each answer option for the Dictatorship-themed situational statements.

For the Jealousy-themed situational statements, a total of 574 responses were recorded for the smaller amount option (e.g., MYR20 if the amount the participant had earlier received was MYR40), 867 responses were recorded for the same amount option (e.g., MYR40 if the amount the participant had earlier received was MYR40) and 607 responses were recorded for the larger amount option (e.g., MYR60 if the amount the participant had earlier received was MYR40). Repeated measures ANOVA shows that there was no significant difference in the decisions made by the respondents for the Jealousy-themed situations $(p=0.06)$. This suggests that respondents reacted similarly towards all options when making decisions for Jealousy-themed situational statements. Figure 4 shows the total number of responses that each answer choice received from the respondents for the Jealousy-themed situational statements.

For the Charity-themed situations, a total of 685 responses were recorded for the "No Charity Work" option, 1,139 responses for the "Charity Work Now" option and 224 responses for the "Charity Work Later" option. Repeated measures ANOVA shows that there was a significant difference in the decisions made by the respondents for the Charitythemed situations $F(1.54,196.08)=26.8, p<0.001$. Results shows that the respondents' choice of "Charity Work Later" option was significantly lower than the "No Charity Work" option $\left(\mathrm{Mean}_{\text {diff }}=-3.60, \mathrm{SE}=0.81\right.$, $p<.001)$ which in turn was significantly lower than the "Charity Work Now" option, $\left(\mathrm{Mean}_{\mathrm{diff}}=-3.54, \mathrm{SE}=1.21, p<0.001\right)$. This suggests that when deciding on Charity-themed situations, respondents were least 
inclined to do charity work for the other person on a later day, even when the amount that the other person will get for that work was the highest. Interestingly, although the number of respondents who were willing to do charity work for the other person immediately is the highest, the number of respondents who were not willing to do charity work for the other person ranks second. Figure 5 shows the total number of responses that each answer choice received from the respondents for the Charity-themed situational statements.

\section{Jealousy-Themed Situational Statements}

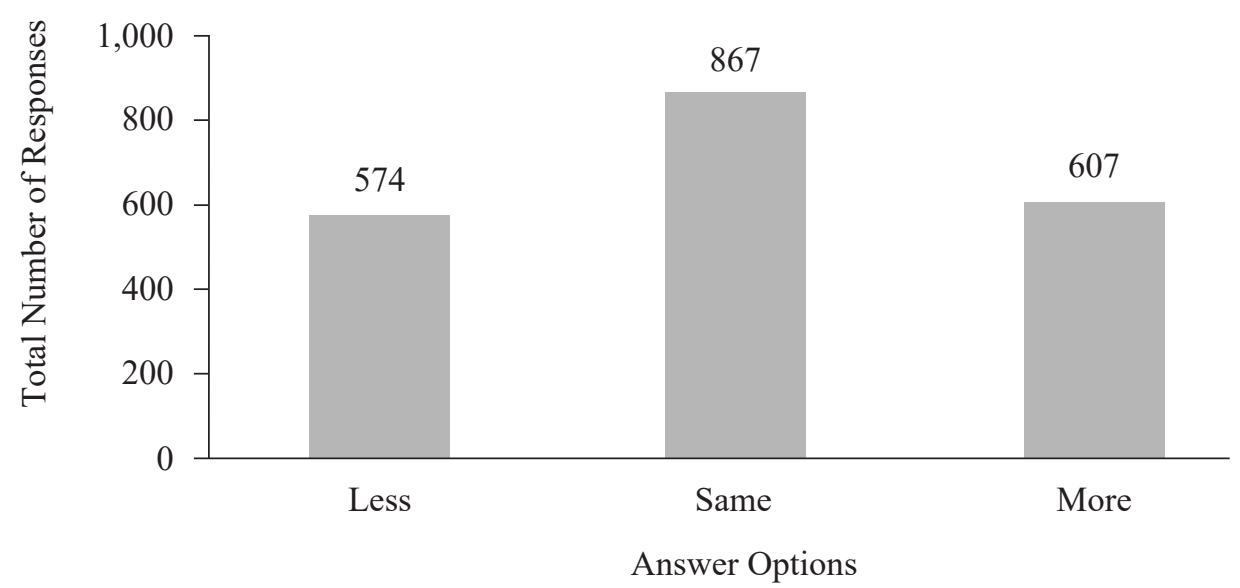

Figure 4: Total number of responses that each answer option for the Jealousy-themed situational statements.

\section{Charity-Themed Situational Statements}

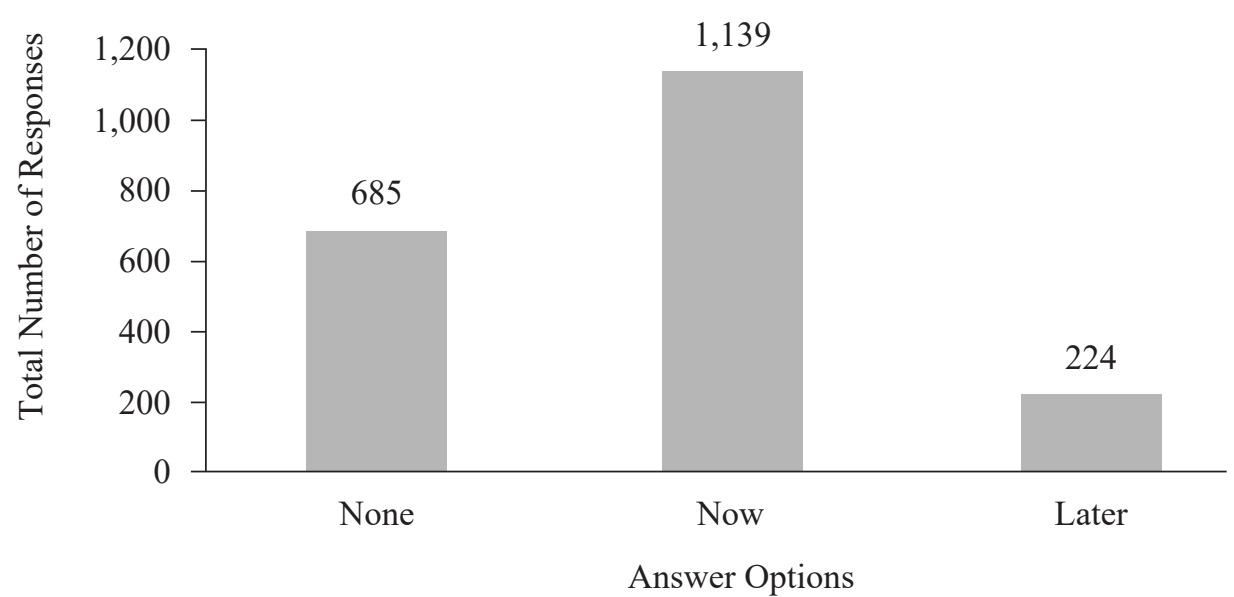

Figure 5: Total number of responses that each answer option for the Charity-themed situational statements. 


\section{Themes with different names}

Following this, further analyses were conducted to investigate if the decisions made by the respondents for the Dictatorship-, Jealousy- and Charity-themed situational statements were different if the names that appeared in the situational statements were Malay or English names. Repeated measures ANOVA showed no significant difference $(p>0.05)$ in both Malay and English contexts for the Dictatorship choices.

\section{Jealousy with different names}

Repeated measures ANOVA showed a significant interaction effect for the name used and the type of Jealousy option $F(1.64,208.63)=4.47$, $p=0.018$, in both Malay and English contexts. A follow up analyses for English and Malay name options indicate a no significant difference for Malay name; however, there was a significant difference for the English name $F(2.0,254.0)=3.16, p=0.04$. However, pairwise comparison indicates no significant difference between Jealousy options in the English name context.

\section{Mean Number of Responses on Jealousy for Different Name Conditions}

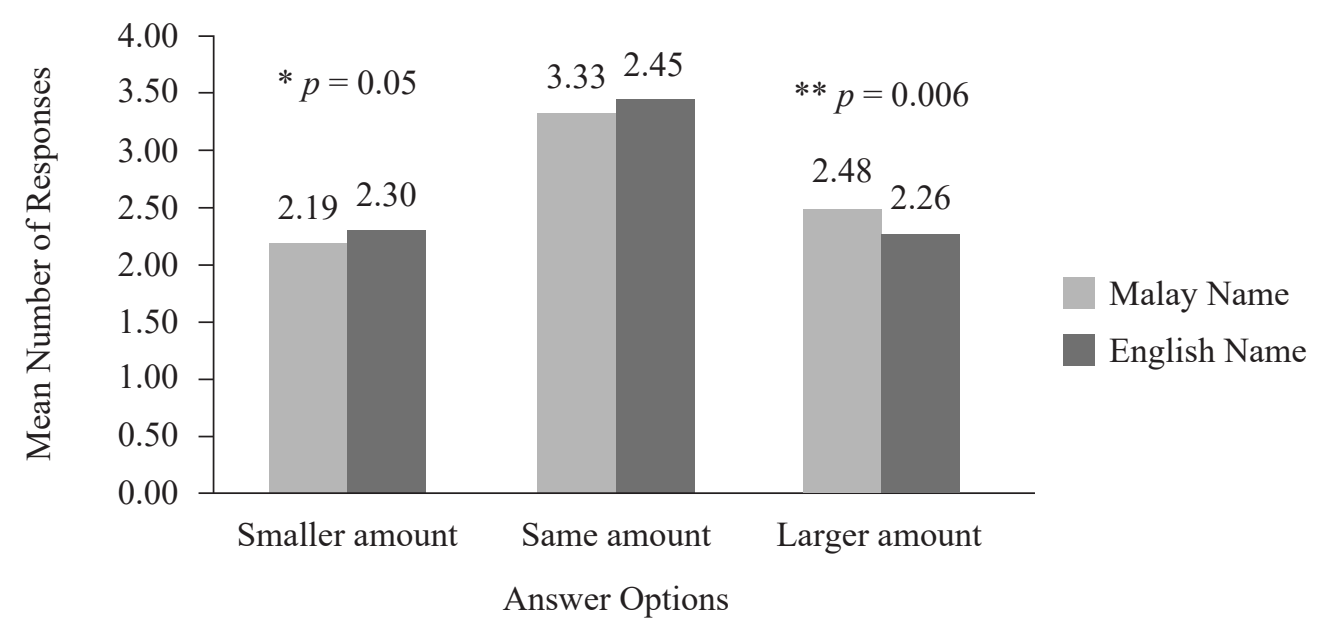

Figure 6: Mean number of responses on Jealousy-themed situations for different name conditions. 
A paired samples $t$-test indicate a significant difference between Malay name $(M=2.19, \mathrm{SD}=3.31)$ and "English name" $(M=2.29, \mathrm{SD}=$ 3.42 ) for the smaller amount option $t(127)=-1.96, p=0.05$, and a significant difference between Malay $(M=2.48, \mathrm{SD}=3.38)$ and English names $(M=2.26, \mathrm{SD}=3.4)$ for larger amount option, $t(127)=2.77$, $p=0.006$. However, there were no difference between the names for the same amount option. Figure 6 presents results on Jealousy based on the different names condition.

\section{Charity with different names}

Repeated measures ANOVA showed a significant interaction effect for the name used and the type of Charity option $F(2.0,254.0)=26.69$, $p<0.001$, in both Malay and English contexts. A follow up analyses for English and Malay name options indicate a significant difference for Malay and English name contexts. The within-subjects effects for Malay name was significant $F(2.0,254.0)=25.75, p<0.001$. Pairwise comparison indicate larger mean $(M=4.41)$ for "Charity Work Now" which is significantly different from "Charity Work Later" $(M=0.891)$, $p<0.001$. "Charity Work Later" is significantly different $(p=0.017)$ from "No Charity Work" option $(M=2.69)$. Bonferroni corrections were applied for the pairwise comparison.

The within-subjects effects for English name was significant $F(1.56,199.05)=27.35, p<0.001$. Pairwise comparison indicate a larger mean $(M=4.48)$ for Charity Work Now option which is significantly different from the "Charity Work Later" option $(M=0.86), p<0.001$. "Charity Work Later" option is significantly different $(p=0.009)$ from the "No Charity Work" option $(M=2.65)$. Bonferroni corrections were applied for the pairwise comparison. Paired samples $t$-test indicate there were no significant difference $(p>0.05)$ between Malay name and English name conditions for all options. Figure 7 presents results on Charity based on different names condition.

\section{Themes with different cultures}

A series of repeated measures ANOVA were conducted to investigate if the decisions made by the respondents for the Dictatorship-, Jealousyand Charity-themed situational statements were different if different elements of culture were or were not included, in the situational statements. 


\section{Mean Number of Responses on Charity for Different Name Conditions}

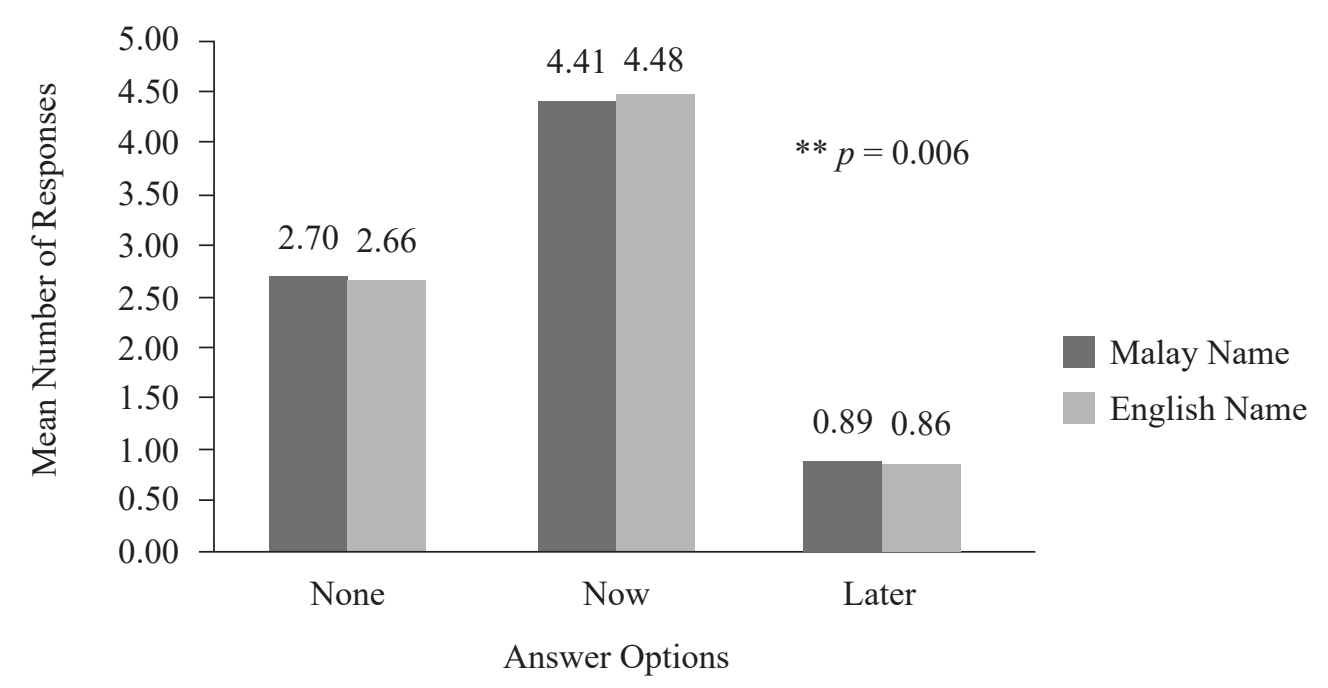

Figure 7: Mean number of responses on Charity-themed situations for different name conditions.

\section{Dictatorship with different cultures}

Results indicate a significant interaction effect for dictatorship theme and culture variables $F(1.31,166.79)=100.18, p<0.001$. To identify where the differences exist, follow up analyses were conducted for dictatorship situational statements after controlling for each cultural factor.

There were significant differences for dictatorship $F(1.23,157)=$ 34.6, $p<0.001$ between the three options. Pairwise comparisons indicate a significant difference for all three options $(p<0.001)$. For dictatorship $40 \%-60 \%$ option, there were significant differences between "Malaysian culture" $(M=0.87)$ and "No culture" $(M=1.84)$ options $(p<0.001)$, and between "Western culture" $(M=0.88)$ and "No culture" $(M=1.84)$ options $(p<0.001)$. However, there was no significant difference between Western and Malaysian cultures $(p>0.05)$.

For dictatorship 50\%-50\% option, there was a significant difference $F(1.20,153.26)=312.39, p<0.001$ between the three options. Pairwise comparisons indicate significant differences $(p<0.001)$ between "Malaysian culture" $(M=2.98)$ and "No culture" $(M=5.91)$, and between "Western culture" $(M=2.98)$ and No culture. However, there was no significant difference between Western and Malaysian cultures $(p>0.05)$. 
For dictatorship $60 \%-40 \%$ option, there was a significant difference $F(1.15,32.8)=6.90, p=0.007$ between the three options. Pairwise comparisons indicate significant differences $(p<0.001)$ between "Malaysian culture" $(M=0.13)$ and "No culture" $(M=0.27)$, and between "Western culture" $(M=0.13)$ and "No culture". However, there was no significant difference between Western and Malaysian cultures $(p>0.05)$. Figure 8 presents results on Dictatorship based on the different culture conditions.

\section{Mean Number of Responses on Dictatorship for Different Culture Conditions}

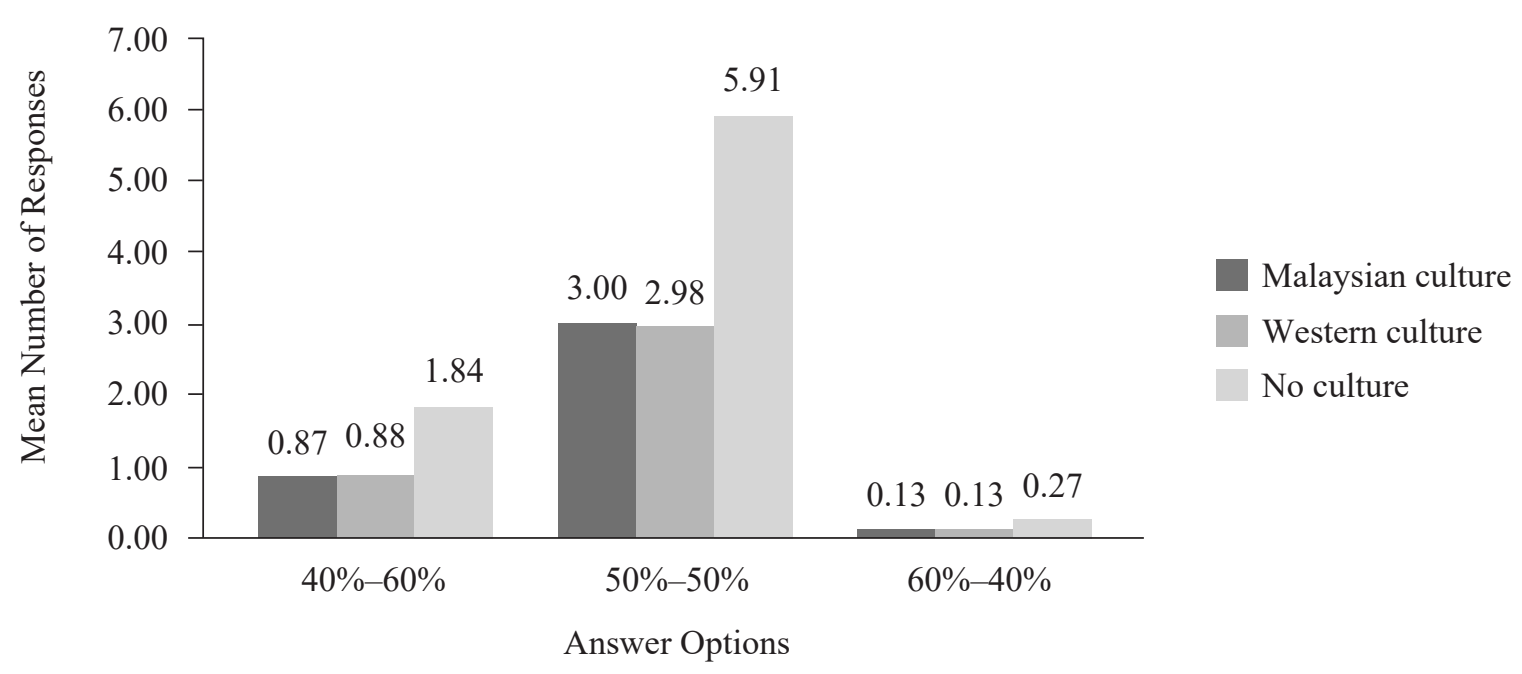

Figure 8: Mean number of responses on Dictator-themed situations for different culture conditions.

\section{Jealousy with different cultures}

When controlled for the smaller amount option, culture was significant, $F(1.09,139.47)=50.36, p<0.001$. Follow up pairwise comparisons indicate significant differences between "Malaysian culture" $(M=1.02)$ and "No culture" $(M=2.34)$, and between "Western culture" $(M=1.13)$ and "No culture". However, there was no significant difference between Western and Malaysian cultures.

For the same amount option, results were also significant $F(1.2,154.42)=72.44, p<0.001$. Pairwise comparisons indicate significant differences $(p<0.001)$ between "Malaysian culture" $(M=1.61)$ and "No culture" $(M=3.42)$, and between "Western culture" $(M=1.73)$ and No culture. However, there was no significant difference between Western and Malaysian cultures $(p>0.05)$. 
For the larger amount option, the results were also significant, $F(1.24,156.87)=30.67, p<0.001$. Pairwise comparisons indicate significant differences $(p<0.001)$ between "Malaysian culture" $(M=1.36)$ and "No culture" $(M=2.23)$, and between "Western culture" $(M=1.14)$ and "No culture". There was also a significant difference $(p<0.01)$ between Western and Malaysian cultures. Figure 9 presents results on Jealousy based on different culture conditions.

\section{Mean Number of Responses on Jealousy for Different Culture Conditions}

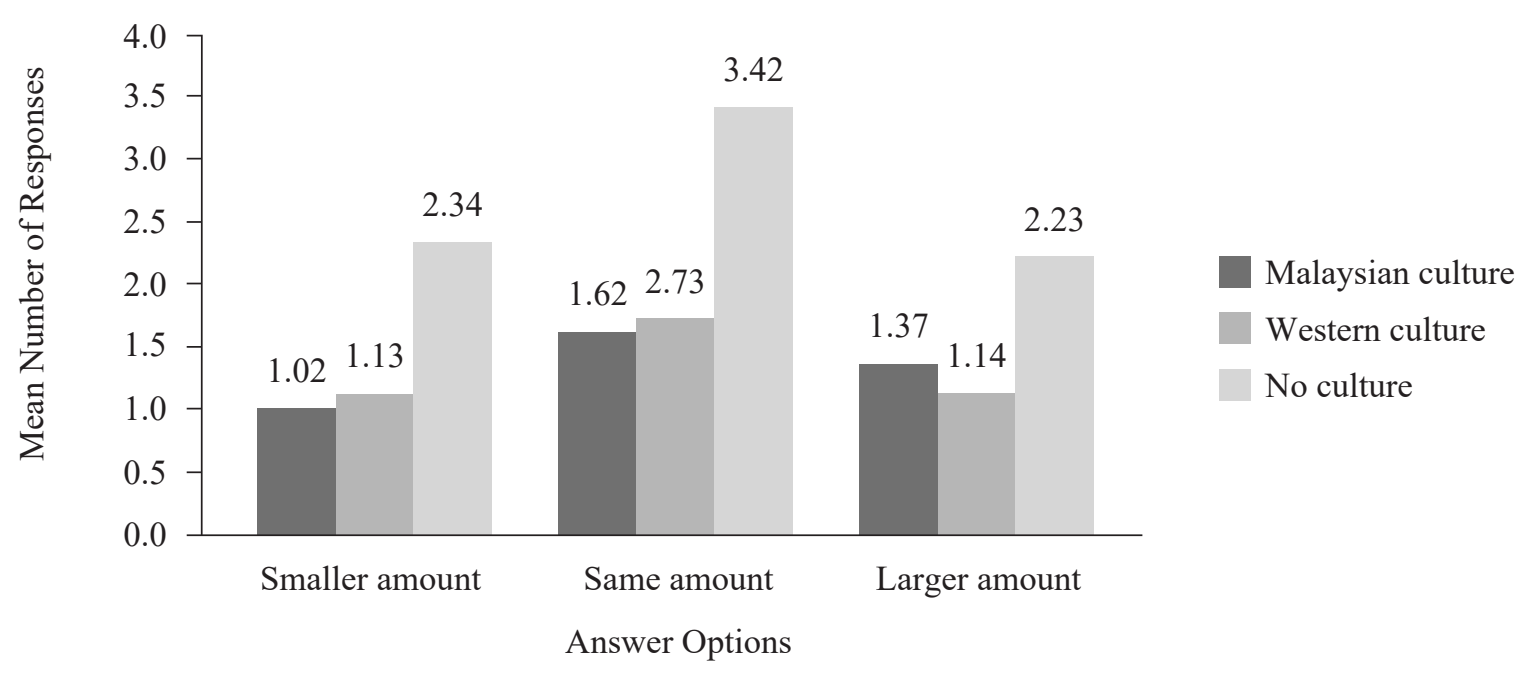

Figure 9: Mean number of responses on Jealousy-themed situations for different culture conditions.

\section{Charity with different cultures}

When controlled for "Charity Work Now" option, results were significant, $F(1.13,143.28)=174.86, p<0.001$. Pairwise comparisons for "Charity Work Now" option indicate significant differences $(p<0.001)$ between "Malaysian culture" $(M=2.20)$ and "No culture" $(M=4.48)$, and between "Western culture" $(M=2.21)$ and No culture. However, there is no significant difference $(p>0.05)$ between Western and Malaysian cultures.

For "Charity Work Later" option, results were also significant $F(1.3,170.55)=12.18, p<0.001$. Pairwise comparisons indicate significant differences $(p=0.001)$ between "Malaysian culture" $(M=0.45)$ and "No culture" ( $M=0.86)$, and between "Western culture" $(M=0.44)$ and "No culture". However, no significant difference $(p>0.05)$ was found between Western and Malaysian cultures. 
For No Charity option, results were also significant, $F(1.09,138.83)$ $=66.3, p<0.001$. Pairwise comparisons indicate significant differences $(p<0.001)$ between "Malaysian culture" $(M=1.34)$ and "No culture" $(M=2.6)$, and between "Western culture" $(M=1.35)$ and "No culture". However, there was no significant difference $(p>0.05)$ between Western and Malaysian cultures. Figure 10 presents results on Charity based on different culture condition.

\section{Mean Number of Responses on Charity for Different Culture Conditions}

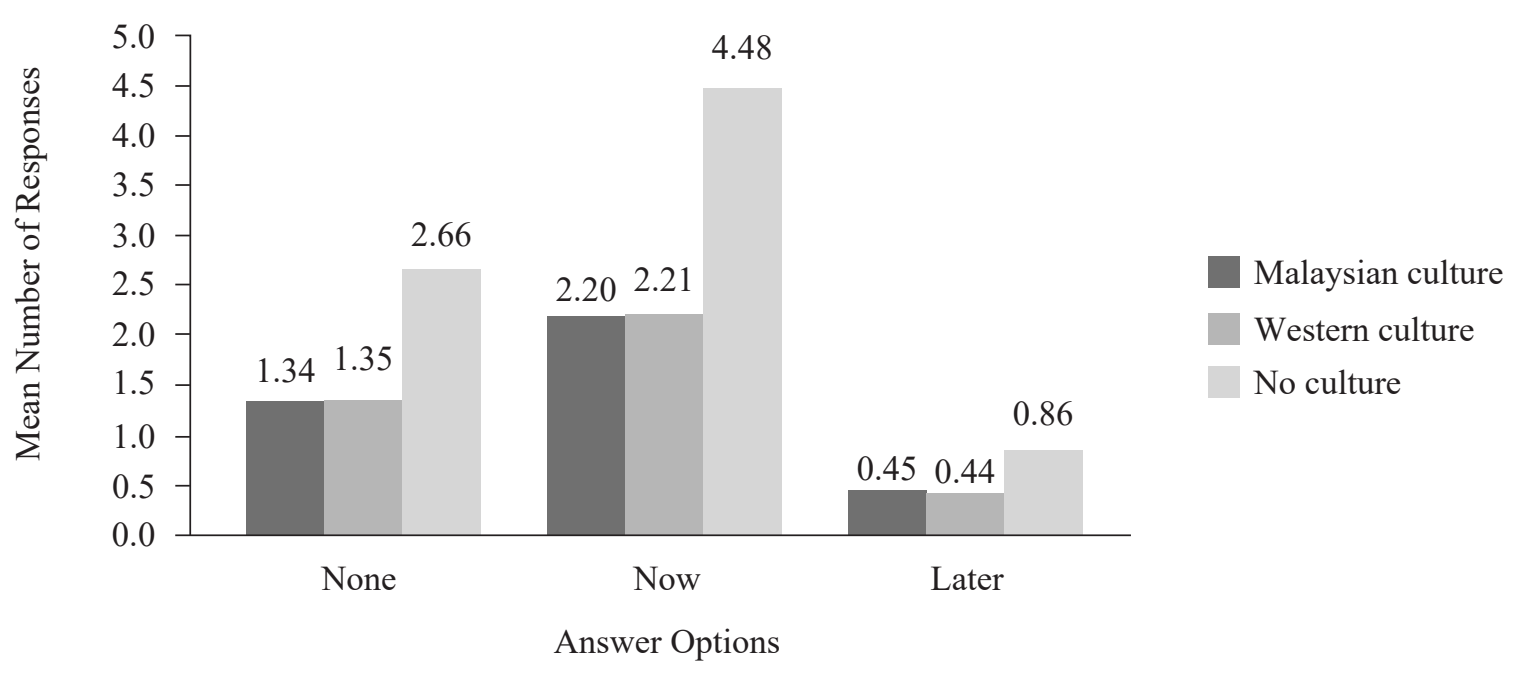

Figure 10: Mean number of responses on Charity-themed situations for different culture conditions.

\section{Themes with different monetary amounts}

Another set of analyses were conducted to investigate if the decisions made by the respondents for the Dictatorship-, Jealousy- and Charity-themed contexts were different if the size of the amount given as the answer options in each situational statement was either larger or smaller (e.g., MYR20, MYR40 and MYR60 vs. MYR200, MYR400 and MYR600). Results showed no significant difference between the theme options and the amount given in each option $(p>0.05)$. There was no interaction effect.

This section has explored the decision-making patterns of the 128 respondents when they read 48 situational statements that are presented in three different themes. There were significant differences in the choices made by the respondents for Dictatorship- and Charity-themed situations, but no significant difference was observed in the Jealousy-themed situations. 
Also, as shown in Table 1 earlier, all 48 situational statements had a combination of the following features: (1) They either have a Malay or an English name mentioned in each of them, (2) They either have Malaysian, or Western, or no cultural elements mentioned in each of them and (3) They either have a smaller amount of money or a larger amount of money to offer as options in each of them.

\section{Factors Influencing Respondents' Social Behaviour}

To investigate whether or not there are factors that influence the social behaviour of the respondents of this study, first, repeated measures ANOVA was conducted for theme options and different languages. Secondly, two separate mixed-model ANOVAs were conducted for theme options and income group, and theme options and language proficiency, where income group and language proficiency were computed as between-subjects factors.

Repeated measures ANOVA was conducted for theme options and different languages to investigate if the responses given by the respondents would be similar or otherwise if the situational contexts that they had to respond to were in different languages (i.e., Malay and English). Results show that there was no significant difference $(p>0.05)$ between the responses gathered from all 128 respondents with regard to the options that they chose for Dictatorship-, Jealousy-, and Charity-themed situational contexts, suggesting that the language in which the situations were presented does not influence the social behaviour of the respondents.

A mixed-model ANOVA was also conducted for each theme (Theme options $\times$ Income group) separately to further investigate if the different responses gathered for each theme vary from one income group to another. Results show that there is no significant difference in the response types between the different income groups $(p>0.05)$ for all three themes suggesting that income group does not influence the social behaviour of the respondents.

Similar to the above, mixed model ANOVA for each theme was conducted separately (Theme option $\times$ Language proficiency) to further investigate if the different responses gathered for each theme vary from the language proficiency of the respondents. Results show that there is no significant $(p>0.05)$ difference in the response types between the respondents with different language proficiency groups for all three themes suggesting that language does not influence the social behaviour of the respondents. 


\section{DISCUSSION}

The current study was conducted to explore the decision-making patterns of Malay-English bilingual Malaysian undergraduates when they read 48 situational statements that were presented to them via an online survey. The situational statements were designed based on three themes, namely, Dictatorship, Jealousy and Charity, which were adapted from Li's (2017) preference games conducted on a group of Chinese-English bilingual undergraduates. Each situational statement came with three-answer options from which a decision was made: $40 \%-60 \%, 50 \%-50 \%$ and $60 \%-40 \%$ options for the Dictatorship-themed situations; a smaller amount, the same amount and a larger amount options for the Jealousy-themed situations; and "No Charity Work", "Charity Work Now" and "Charity Work Later" options for the Charity-themed situations. The current research was conducted based on the assumptions that: (1) the decisions that individuals make reflect their social behaviour (e.g., the less amount they give the other person, the less prosocial they are), (2) Malaysians are Malay-English bilinguals, (3) a household with a total income lower than MYR3,500 is considered as a lower-income household and (4) Malaysians, being an oriental culture, is a collectivistic culture, which makes them a more prosocial culture.

Based on the definition given, prosocial individuals are expected to act in a behaviour that would benefit the other persons rather than a behaviour that would benefit themselves (Cherry 2018). They would do anything to help, comfort, share and cooperate with the other individuals as long as the feelings, well-being, and the rights of the other individuals are taken care of. To explore if the respondents of the current study are prosocial individuals or otherwise, the decisions that they made for Dictatorship-themes were analysed. Following the definition above, the following can be used as a working definition: (1) If the respondents were to share with the other individuals an equal amount of money, they are prosocial individuals and (2) If they were to share with the other individuals more than they amount that they would keep to themselves, they are true prosocial individuals. As a matter of fact, they may even be described as altruistic because their act suggests that they are willing to sacrifice what they are getting so that the amount that the other individual is getting can be increased (c.f. Moreno et al 2019); (3) If they were to share with the other individuals less than the amount that they would keep to themselves, they are not prosocial individuals. 
Given that Malaysians are considered coming from a collectivist culture which emphasises on values such as harmony, sharing, and caring for others (Winskel et al. 2016), it was assumed earlier that the respondents in this study would act in a prosocial manner in their decision-making. It was expected that a majority of them would be willing to share a larger portion of the money they received with the other person, that they will not be jealous of the other person's wealth and that they are willing to work for a charity body so that the other person will get a larger amount of money.

From the responses gathered from the Dictatorship- and Charitythemed situational statements, it appears that only a small portion of Malaysians undergraduates (3\% for Dictatorship-themed and $11 \%$ for Charity-themed) who responded to the situational statements seemed to prioritise the welfare of others over their self-interest. These are those who were willing to give others a larger portion of money and keep only the smaller portion to themselves; they were also willing to work on a later date for the other person so that the other person can get a larger amount of money, even though the respondents did not know what kinds of obstacles they may encounter in the future. This echoes what an altruistic behaviour is, which is a type of prosocial behaviour, that describes an individual who will give more to others than keeping more for themselves. Nevertheless, a great majority of the undergraduates who participated in the study (74\% for Dictatorship-themed and 56\% for Charity-themed) were willing to share their portion equally with the other person, and were also willing to do charity work for the other person immediately for a smaller amount of money. Although this behaviour may not be totally altruistic, the fact that they were willing to share the same amount of money and work for the other person immediately makes them somewhat prosocial in nature.

Despite this, there is a good portion (22\%) of undergraduates who would rather give a smaller portion of money to the other person so that they could keep the larger amount for themselves for the dictatorship-themed situational statements. There is also a good portion (33\%) of undergraduates who would not do charity work for the other person at all. These two acts do not echo prosocial behaviours. Although no interview was conducted after the survey to investigate why these group of respondents chose such options, based on past studies, it is said that the individuals could have acted in such a way because of the fact that "prosocial behaviour is costly, directing resources away from the self towards other" (Piff et al. 2010). This is a behaviour that is assumed to be quite common among individuals from the lower-income group since they are expected to focus more on 
themselves and their immediate needs because of the fewer economic resources (e.g., Oakes and Rossi 2003). However, further analysis that shows that there is no interaction between the response types and the income group of the respondents suggests that the respondents' choices for these two themes are not influenced by the income group in which they belong. When making decisions for Jealousy-themed situations however, no difference in the decisions made was observed.

Whether an individual is prosocial or otherwise is not necessarily determined by the community the person is from. An individual from an individualistic culture may be more prosocial than another individual coming from a collectivistic culture. This is because, studies, according to Knafo-Noam and Markovitch (2015), have shown that parents play a role in shaping their child's behaviour through modelling and hands-on behaviours. A study by Winskel et al. (2013), for example, also found no significant difference between the parenting style of Malaysians and those of Anglo-Australians and they attributed this to the fact that the parenting styles of some Malaysians may be influenced by Western cultural goals and values which are presumed as more modern. According Kağitcibaşi (2007), there appears to be a close link between increased modernity and individualism; this may be the reason why despite coming from a collectivistic community, there are individuals in the current study who have the tendency to choose options that are less prosocial, i.e., options that centres more about themselves (so that they get more money) than the other individual (so that the other individual gets a smaller amount). The statistical analysis conducted in this study is to investigate if the proficiency level of the respondents has an effect on the respondents' social behaviour also supports this.

Past studies suggest that individuals tended to be more prosocial to the other individual if this other individual comes from the same group as they are. In this study, a Malay name (i.e., Hamidon) and a Malay cultural element were included in the situational statements to represent the individuals from the same culture. Although it is expected that respondents will respond in a less prosocial manner when the names of a person not from their culture (in this study, Hamilton) is used in the situational statements, this study shows that Malaysian undergraduates behaved similarly. This suggests that among Malaysians, ethnicity is not a factor that determines whether one should be prosocial or otherwise. This could be due to the fact that Malaysia is a multi-ethnic society. 
It was also observed that the choice made by the respondents when "No culture" is mentioned in the situational statements was significantly different from when the "Malaysian culture" and or the "Western culture" is mentioned in the situational statements. The difference is, however, due to the design of the statements - the number of "No culture" situational statements (8) doubles the number of "Malaysian culture" (4) and "Western culture" (4) situational statements. In future, when designing such situational statements, there should not be any "No culture" situational statements; instead, the number of situational statements for both "Malaysian culture" and "Western culture" should be increased to 8 each. However, the fact that the difference between "Malaysian culture" and "Western culture" is not significant suggests that cultural elements that are embedded in the situational statements do not play a role in decision-making among the Malaysian undergraduates.

Past studies also show that income group has an influence on the social behaviour of individuals. Although it was earlier hypothesised that Malaysian undergraduates coming from different income groups could make different decisions, the current study, however, shows that there is no interaction between income group and the choices that the respondents made. This suggests that the socioeconomic background of individuals does not influence their social behaviour.

The current study also shows that language has no influence on the decisions that the respondents made although such a hypothesis was made based on Li's (2017) hypothesis and the findings of the study by Keysar et al. (2012) and Winskel et al. (2016). Such a discrepancy is probably due to the fact that the level of proficiency of the respondents of the current study in the second language (i.e., English language) is higher than the level of those in the past studies. The respondents in Keysar et al. (2012) and Winskel et al.'s (2016) study, for example, regarded the other language as "foreign language" whereas those in the current study regarded the other language as a "second language" (a second language is a language that is more readily available in an individual's environment than a foreign language. See Salehuddin (2018) for an elaborate discussion on this). Because of this, the use of a foreign language may result in a greater emotional distance than the use of a second language. Although almost half of the respondents in the current study reported that their they are more proficient in the Malay language than in the English language, in reality, they have all learned the English language formally since they were in their primary 
schools, in which, English is officially taught as a second language. This results in the use of different languages in presenting the situational statements having no effect on the decisions that the respondents made.

\section{CONCLUSION}

The decision-making patterns of a group of Malay-English bilingual Malaysian undergraduates $(n=128)$ from a mixed income group based when reading 48 Malay-English bilingual situational statements was explored. This was done by analysing the choices that they made when reading situational statements that were presented to them in three different themes, namely, Dictatorship, Jealousy and Charity.

This study has shown that the social behaviour of Malaysian undergraduates varies; conclusions cannot be made as to whether they are prosocial or otherwise. Although results show that the majority of them show prosocial behaviours in the different situational statements that they read, a significant few did show behaviours that do not resemble prosocial behaviours. Also, although past studies showed that income group, language proficiency, and the language used in which the studies were conducted did influence the decisions made, this study shows that none of those have an impact on the decisions that the respondents made. Religion and modernity could be two of the factors that might be underlying the decision-making patterns of the respondents of this study; these two, however, have not been explored and may be factors that should be investigated in future studies.

This study has its own limitations. Firstly, the language proficiency level identified in this study was based on the respondents' perception rather than on a standardised test. Although the latter is more preferred in certain in language-related research, the former has widely been used in non-language-related research. Hence, using a standardised test in classifying the respondents may only be another alternative in categorising the respondents' level of proficiency in the language. Secondly, the respondents were all from the same university. Although some may argue that this may not be a true representation of Malaysian undergraduates in general, the facts that the undergraduates were from a public university whose students may come from different socio-economic, ethnic and linguistic backgrounds justify the selection of the sample of this study. Finally, the findings of this study are solely based on respondents' responses towards situational statements that were presented with multiple answer 
options. Perhaps, such a study can be strengthened through an interview conducted after responding to the situational statements to justify the selection of the answers by the respondents. This is not necessary for now, however, since the current study is quantitative in nature.

There are a couple of implications to this study. Firstly, since decisionmaking may not always be influenced by the society, language and income group, the act of making decisions can actually be trained. Hence, this study proposes that individuals should be given the opportunity to learn how to make the right decisions objectively and not to be dependent on factors that might influence them emotionally. Finally, since decision-making takes place at all levels in all individuals, training to make objective decisions should not only be focused on those who are at the top of an organisational hierarchy; individuals from all walks of life deserve to be empowered with knowledge on how best decisions can be made regardless of the kinds of decisions that they have to make.

\section{ACKNOWLEDGEMENTS}

This work was supported by Universiti Kebangsaan Malaysia under Dana Cabaran Perdana DCP-2017-014/1. Special acknowledgement is given to all 128 respondents who responded to the survey.

\section{COMPLIANCE WITH ETHICAL STANDARDS}

Ethics Approval (UKM PPI/111/8/JEP-2018-339) was obtained before the commencement of this research. The research was also conducted in the absence of any commercial or financial relationships that could be construed as a potential conflict of interest.

\section{NOTES}

* Khazriyati Salehuddin (PhD) is an Associate Professor and a Psycholinguist at the Centre for Research in Language and Linguistics, Faculty of Social Sciences and Humanities, Universiti Kebangsaan Malaysia. She received her $\mathrm{PhD}$ in Psycholinguistics from Western Sydney University in the year 2010. Khazriyati has a special interest in language and cognition; she has led several research groups related to the area, including two national-level grants, namely Qur'anic Memorisation Techniques: A Psycholinguistic Module for Non-Arabic-Speaking Malay Speakers 
(FRGS) and Exploring the Cognitive and Perceptual Processes in Reading among Malaysian Readers (ERGS). Khazriyati uses various data collection methods in her research and has published several journal articles, books, and book chapters on the area. One of her works is published in South and Southeast Asian Psycholinguistics by Cambridge University Press and her single-authored book entitled Psikolinguistik: Penerokaan Minda Berlandaskan Bahasa [Psycholinguistics: A Language-based Exploration of the Mind] is published by UKM. She is currently the Head of English Language Studies Programme at her faculty and is a member of the Language and Cognition Research Group (LCRG) at her research centre. Khazriyati teaches and supervises both undergraduate and postgraduate students for two different programmes namely English Language Studies and Linguistics. Her full CV is available at goo.gl/ rskBFV.

\section{REFERENCES}

Batson, C. D. 1998. Altruism and prosocial behavior. In The Handbook of social psychology, eds. Gilbert, D. T., Fiske, S. T. and Lindzey, G., 282-316. Boston, MA: McGraw-Hill.

Bochner, S. 1994. Cross-cultural differences in self-concept. Journal of Cross-Cultural Psychology 25: 273-283. https://doi.org/10.1177/0022022194252007

Burns, D. J. and Brady, J. 1992. Cross-cultural comparison of the need for uniqueness in Malaysia and the United States. Journal of Social Psychology 132: 487-495. https://doi.org/10.1080/00224545.1992.9924728

Cherry, K. 2018. The basics of prosocial behaviour. Verywell mind. https://www. verywellmind.com/what-is-prosocial-behavior-2795479.

Creo, R. A. 2018. The master mediator, green: The color of money, and the color of envy. Alternatives 36 (6): 89-91. https://doi.org/10.1002/alt.21741

Davidson, A. W. and Yaneer, B. Y. 2006. Environmental complexity: Information for human-environment well-being. In Unifying themes in complex systems, eds. Yaneer, B. Y. and Ali, M., 157-168. Berlin/New York: Springer. https://doi.org/ 10.1007/978-3-540-35866-4_16

Deck, C. and Jahedi, S. 2015. The effect of cognitive load on economic decision making: A survey and new experiments. European Economic Review 78: 97-119. https://doi.org/10.1016/j.euroecorev.2015.05.004

Dietrich, C. 2010. Decision making: Factors that influence decision making, heuristic used, and decision outcomes. Inquiries Journal/Student Pulse 2 (2). http://www.inquiriesjournal.com/a? id=180

Kağitcibaşi, C. 2007. Family and human development across countries: A view from the other side, 2nd ed. Sussex, UK: Psychology Press.

Kebede, B. et al. 2018. Inequality, envy and personality in public goods: An experimental study. CSAE working paper series 2018-10. Centre for the Study of African Economies, University of Oxford.

Keshavarz, S. and Baharudin, R. 2009. Parenting style in a collectivist culture of Malaysia. European Journal of Social Sciences 10: 66-73. 
Keysar, B. et al. 2012. The foreign-language effect: Thinking in a foreign tongue reduces decision biases. Psychological Science 23 (6): 661-668. https://doi.org/ $10.1177 / 0956797611432178$

Knafo-Noam, K. and Markovitch, N. 2015. Individual differences in prosociality: The role of parenting, temperament, and genetics. Encyclopedia on early childhood development. http://www.child-encyclopedia.com/prosocial-behaviour/accordingexperts/individual-differences-prosociality-roles-parenting.

Kruglanski, A. W. and Giegerenzer, G. 2011. Intuitive and deliberate judgments are based on common principles. American Psychological Association 118 (1): 97-109. https://doi.org/10.1037/a0020762

Li, K. K. 2017. How does language affect decision-making in social interaction and decision biases? Journal of Economic Psychology 61: 15-28. https://doi.org/10.1016/j. joep.2017.03.003

Mani, A. et al. 2013. Poverty impedes cognitive function. Science 341 (6163): 1169-1169. https://doi.org/10.1126/science.1246799

Moreno, A. 1. et al. 2019. Emotions of altruism, envy and guilt: Experimental evidence. 2019. MPRA Paper No. 94096. https://mpra.ub.uni-muenchen.de/94096/

Mullainathan, S. and Shafir, E. 2013. Scarcity: Why having too little means so much. Times Books/Henry Holt and Co.

Nunes, I. et al. 2015. Decision making with natural language based preferences and psychology-inspired heuristics. Engineering Applications of Artificial Intelligence 42: 16-35. https://doi.org/10.1016/j.engappai.2015.03.008

Oakes, J. M. and Rossi, P. H. 2003. The measurement of SES in health research: Current practice and steps toward a new approach. Social Sciences and Medicine 56: 769 784. https://doi.org/10.1016/S0277-9536(02)00073-4

Obi, J. N. and Agwu, E. 2017. Effective decision-making and organizational goal achievement in a depressed economy. International Journal of Research and Development Studies 8 (1): 1-10.

Panpatte, S. and Takale, V. D. 2019. To study the decision making process in an organisation for its effectiveness. The International Journal of Business Management and Technology 3 (1): 73-78.

Perera, -W. A. H. et al. 2021. EEG sebagai satu kaedah berkesan untuk memahami aktiviti neural berkaitan kemiskinan. Akademika: Journal of Southeast Asia Social Sciences and Humanities 91 (1): 165-179.

Piff, P. K. et al. 2010. Having less, giving more: The influence of social class on prosocial behaviour. Journal of Personality and Social Psychology 99(5): 771-784. https://doi.org/10.1037/a0020092

Salehuddin, K. 2018. Psikolinguistik: Penerokaan minda berlandaskan bahasa [Psycholinguistics: Language-based exploration of the mind]. Selangor, Malaysia: UKM Press.

Sheehy-Skeffington, J. 2020. The effects of low socioeconomic status on decision-making processes. Current Opinion in Psychology 33: 183-188. https://doi.org/10.1016/ j.copsyc.2019.07.043

Sheehy-Skeffington J. and Rea J. 2017. How poverty affects people's decision-making processes. York, UK: Joseph Rowntree Foundation. 
Sisco M. R. and Weber E. U. 2019. Examining charitable giving in real-world online donations. Nature Communications 10 (1): 3968. https://doi.org/10.1038/s41467 $-019-11852-z$

Snibbe, A. C. and Markus, H. R. 2005. You can’t always get what you want: Educational attainment, agency, and choice. Journal of Personality and Social Psychology 88 (4): 703-720. https://doi.org/10.1037/0022-3514.88.4.703

Stellar J. E. et al. 2012. Class and compassion: Socioeconomic factors predict responses to suffering. Emotion 12 (3): 449-59. https://doi.org/10.1037/a0026508

Trope, Y. and Liberman, N. 2010. Construal-level theory of psychological distance. Psychological Review 117 (2): 440-463. https://doi.org/10.1037/a0018963

Twenge, J. M. et al. 2007. Social exclusion decreases prosocial behaviour. Journal of Personality and Social Psychology 92 (1): 56-66. https://doi.org/10.1037/0022 $-3514.92 .1 .56$

Winskel, H. et al. 2016. Decision-making and the framing effect in a foreign and native language. Journal of Cognitive Psychology 28: 427-436. https://doi.org/10.1080/ 20445911.2016 .1139583

Winskel, H., Salehuddin, K. and Stanbury, J. 2013. Developmental milestone expectations, parenting styles and self-construal in Malaysian and Australian caregivers. Kajian Malaysia 31 (1): 19-35.

Zsambok, C. E. 1997. Naturalistic decision-making: Where are we now? In Naturalistic decision-making, eds. Zsambok, C. E. and Klein, G. Mahwah, NJ: Lawrence Erlbaum Associates. 